\title{
浅谈初中生物课堂有效提问的策略
}

\author{
卢萍香 \\ 江西省贑州市南康区龙回中学 \\ DOI: $10.32629 /$ jief.v2i5.1438
}

[摘 要] 在进行初中生物教学的过程中, 课堂提问能够增加学生的讨论话题, 而且学生能够根据教师提出的问题明确教学内容, 引发学生对 问题的思考, 使学生积极投入到课堂教学中。教师也能够从学生的回答中得到反馈, 灵活调整课堂教学活动, 优化课堂教学的结构。本文针 对初中生物有效提问的策略展开探讨。

[关键词] 初中生物; 有效问题; 策略研究

中图分类号: G633.91 文献标识码: A

随着素质教育的推广, 课堂教学不再只关注学生的学习成绩和固定 思维的培养, 而是鼓励学生发散思维, 积极思考, 提升学生的学科素养。 因此, 初中生物教师要善于利用课堂提问, 调动学生的思维能力, 激发 学生的想象力和创造力, 提高学生的学习能力, 促进课堂教学质量和效 率的提升。

\section{1 初中生物课堂提问存在的问题}

在新课改背景下, 大部分教师认识到了课堂提问的重要性, 能够运 用有效的课堂提问改变枯燥、无趣的课堂氛围, 打破了传统教学理念对 学生的束缚, 加强了师生间的交互。但在初中生物教学中, 还存在着一 些问题, 首先, 有些初中生物教师的提问太过形式化, 虽然看起来活跃 了课堂教学的氛围, 顺应了新课改的要求, 但实际上只是将传统教学模 式中的单向传输信息变成了单一的提问, 教师提出引导性的问题, 让学 生说出指定的答案, 没有让学生进行独立的思考, 无法使课堂教学效率 得到提升。教师只是为了提问而提问, 没有考虑到问题给学生带来的影 响, 导致了课堂提问形式化严重。教师设计的课堂问题涉及到的知识面 狭窄, 缺乏了知识的层次性, 只能促进一小部分学生的进步, 无法实现 高效的课堂教学。

\section{2 初中生物课堂有效提问的策略}

2.1 创设良好的教学情境, 活跃课堂教学的气氛。

在初中生物的教学中, 教师可以通过良好的教学情境, 引出课堂提 问, 增加教师与学生之间的交流合作, 激发学生对知识的好奇心和求知 欲, 活跃了课堂教学的氛围, 促进课堂教学的顺利开展。例如在《形形 色色的生物》的教学中, 利用多媒体为学生展示关于不同生物的图片, 让学生思考哪些是生物, 为什么? 在以此来吸引学生的注意力, 调动学 生的学习热情, 在回答问题后, 教师可以接着提问: 它们之间有什么共 同之处? 使学生了解生物都是有生命的。之后教师可以进行适当的拓展, 让学生想一想: 生物维持生命的必备因素有哪些? 以此来发散学生的思 维, 引发学生的思考和讨论, 顺利引出接下来的教学内容, 激发学生对 生物的学习兴趣。

2.2 设计科学的课堂问题, 激发学生学习积极性。

在设计课堂提问时, 教师要深入了解学生的学习能力和接受能力, 增强课堂提问的科学性, 提出符合学生认知水平的问题, 照顾到学生的 全面发展, 促进学生生物能力的进步, 使学生能够举一反三, 提高对生 物组织的认识。有些教师在教学中只喜欢对学习能力强的学生记性提问, 忽略了其他学生的学习体验, 不利于班级整体水平的发展, 也不符合新 课标的要求。例如在《光合作用》的教学中, 先简单想学生讲述光合作
用的必备条件、光合作用的影响和光合作用需要的因素, 培养学生热爱 大自然, 爱护植物的品质。之后在教学中可以进行分层提问, 对学习能 力较强的学生可以在进行光合作用的试验中提问: 绿叶在光下会不会产 生淀粉, 光是光合作用的必要条件吗? 对于学生能力稍差的学生可以提 问: 绿色植物进行光合作用的产物是什么? 尝试写出光合作用的表达式 等基础性的内容, 为学生树立生物学习的自信心, 使全体学生在提问中 都能有所收获, 促进学生科学态度和素养的培养。

2.3 把握好课堂提问的时机, 增加提问的有效性。

课堂提问的有效性与教师提问的时机有着直接关系, 想要找到教学 与提问的契合点, 需要教师合理设置教学流程, 结合课堂教学的进度, 做好教学备课, 以此来提高课堂教学的有效性。课前、课中、课后提出 的问题内容是不同的, 以《种子萌发形成幼苗》教学为例, 在课前, 教 师要利用课堂提问引出新课内容, 这时就可以利用直接提问引起学生的 注意, 如: 同学们, 你们知道植物的幼苗是怎么来的吗? 一颗种子需要 经历哪些成长才能成为参天大树? 这样就能够使学生了解到本节课的教 学内容。之后, 在教学中的提问需要促进课堂教学的发展, 实现教学的 任务, 因此, 这时的课堂提问带有很强的目的性, 如提出: 不同的种子 有着不同的形态, 那它们的结构会是不同的吗? 这样就能引发学生的思 考, 加深学生对教学知识的认知。在教学快要结束时, 教师需要帮助学 生对教学内容进行归纳总结, 加深学生对知识的印象, 如提出: 同学们, 在这节课中大家了解了多少关于种子的奥秘呢? 让学生在小组内分享自 己的收获, 帮助学生梳理知识点。

\section{3 结束语}

综上所述, 想要在初中生物教学中开展有效地课堂提问, 需要教师 结合学生的实际情况, 有针对性的提出问题, 引导学生理解教学知识, 提高学生的学习效率。在进行提问时, 教师创设出良好的教学环境, 提 高问题的科学性, 把握好课堂提问的时机, 以此来增加师生间的对话, 顺利实现课堂教学的目标。

\section{[参考文献]}

[1]刘宏伟. 浅析初中生物课堂有效提问策略 [J]. 学周 刊,2018(15):45-46.

[2]马秀梅.初中生物课堂教学中如何进行有效提问 [N]. 发展导 报,2017-10-24(030).

[3]李桂善.核心素养视角下初中生物课堂的教学现状与应对策略 [J].新课程,2020(37):52. 